\title{
THE BENEFITS AND BARRIERS OF EXERCISE FOR THE PHYSICAL HEALTH OF OLDER WOMEN
}

\author{
A. Tinker, L. Molloy, I. Monks, L. Pennells, E. Russell, E. Haines
}

\section{Introduction and overview}

It is well known that exercise has beneficial effects on physical and mental health and wellbeing. Most research has taken place in young and middle aged groups. Less is known about older people, whom we define as 50 years and over, and even less about women. In this paper we consider particular groups where the risk may be the greatest. This includes those with functional limitations especially those who are frail, with eating problems, at the menopause, at risk of falls and from black and minority ethnic groups. For each of these groups the benefits and barriers are discussed. The focus of this article is on physical problems. .

\section{Defining the terms}

There is a distinction between physical activity and exercise and these terms are now defined.

\section{Physical activity}

There is considerable evidence about physical activity in general and its beneficial effects (1) (2). In the Health Survey for England 2012 it was stated that 'Physical inactivity contributes to a wide range of diseases, including psychological distress and depression, as well as being a major cause of obesity and diabetes. Conversely, regular physical activity brings a wide range of health benefits. Lack of physical activity is the fourth most important risk factor worldwide for chronic non communicable disease after tobacco use, raised blood pressure and hyperglycaemia'.(3Chapter 2 p.3). There is also 'a clear causal relationship between the amount of physical activity people do and all-cause mortality' (4p.10)

Further, there is convincing evidence about the effects of physical activity, specifically in older people. The report and guidelines 'Start Active, Stay Active' by the

Institute of Gerontology, King's College London, United Kingdom

Corresponding Author: Professor Anthea Tinker, Institute of Gerontology, King's College London, United Kingdom, anthea.tinker@kcl.ac.uk

Received December 19, 2016

Accepted for publication February 14, 2017
Chief Medical Officers from the four home UK countries records this. They say 'drawing from recent systematic reviews of the literature, encompassing both experimental and observational research, the evidence is strong that physically active adults aged 65 years and over have higher levels of cardio-respiratory fitness and physical function, improved disease risk factor profiles and lower incidence of numerous chronic non-communicable disease than those who are inactive. Engaging in physical activity carries very low health and safety risks for older adults. In contrast, the risks of poor health as a result of inactivity are very high' (4 p. 38).

We distinguish physical activity from exercise. It is exercise that is the concern of this article and this is defined below.

\section{Exercise}

Exercise is a subset of physical activity (5p. 126). The American Council on Exercise (ACE) defines it as 'movement that is carried out by the skeletal muscles that requires energy. In other words, any movement one does is actually physical activity. Exercise, however, is planned, structured, repetitive and intentional movement intended to maintain physical fitness' (6p1). They add that the movement is intended to improve or maintain physical fitness (6). They claim that exercise also assists with the improvement of physical fitness which consists of cardiorespiratory fitness, muscular strength fitness, muscular endurance fitness, flexibility fitness and body composition.

The Department of Health in England (DH), the Scottish Office (SG), the Welsh Office (WO) and the Department of Health in Northern Ireland (7) have issued a Fact Sheet giving guidelines 'Physical activity guidelines for older adults (65+ years) which includes examples of exercise such as ballroom dancing (7). They also distinguish between moderate intensity physical activities which will cause older adults to become warmer and breathe harder and their hearts to beat faster but they should still be able to carry out a conversation. An example is ballroom dancing. Vigorous intensity physical activities, such as running, will cause older 
adults to become warmer and breathe harder and their hearts to beat faster making it more difficult to carry on a conversation. Activities to strengthen muscles using body weight or working against a resistance include using all major muscle groups such as dancing or chair aerobics. Activities to improve balance and coordination may include Tai Chi and Yoga.

There is convincing evidence to support the association between increased physical activity, participation in exercise and improved health in older adults (2). There is also research on the value of exercise specifically for women (8). There is less on the types of older women who would benefit and we draw together some of the evidence.

\section{Older women}

The focus of this article is older women whom we define as the UK Department for Work and Pensions (DWP) does for as all aged 50 and over (9). Although the focus is on women we note any major differences between men and women where they are significant.

\section{The benefits of exercise for older women}

There are numerous well-recognised benefits of exercise, from prevention of disease and disability to increased well-being (10). In older people, quality of life can be improved through reductions in the risk of developing age-related diseases (11) such as diabetes (12), osteoporosis (13) and cardiovascular disease (14). There are also more specific benefits of exercise which are particularly relevant for certain groups of older women.

Firstly, there are benefits for those who have functional limitations, which are shown to increase exponentially with age (15). Most research supports exercise as an essential intervention in the prevention or amelioration of functional limitations $(15,16)$. A sedentary lifestyle has been shown to increase likelihood of disability or disease; a study of 1002 disabled older women established an inverse correlation between disability and physical activity, where the most physically active of the cohort had greatest strength (17). Additionally, a prospective study calculated a $25 \%$ reduction in hospital admissions for older women who walked for more than four hours a week, compared to controls (18). Regular walking has also been associated with a two-fold reduction in lower body disability compared to controls (19). Furthermore, the incidence of stroke, which is a leading cause of functional limitation in older women, was significantly lower in older women who reported regular exercise and physical activity (20). Another leading cause of functional limitation among older women is osteoarthritis (OA), often cited as a barrier to exercise (21). However, research shows exercise to be an effective strategy for preventing ADL disability among those with knee OA (22). The numerous benefits of exercise on functional limitations are considered to be partly as a result of improvements in muscle strength (23) and partly due to the role of exercise in protecting against chronic illnesses, including arthritis and obesity, which often lead to functional limitations (15).

As well as preventing or decelerating disability and disease rates, exercise has been proven to lower mortality from key diseases. The Framingham Heart Study demonstrated a significant decline of around 30\% in allcause mortality amongst older women who exercised (24). A statistically significant $(\mathrm{P}<0.001)$ prospective study by Nicklett (25), also demonstrated increased survival rates in the most physically active women when compared to controls. Moreover, a study of over 10,000 older American adults participating in the Established Populations for Epidemiologic Studies of the Elderly (EPESE) determined a two-fold increase in death without disability among the most active participants when compared to the most sedentary (26).

It has been postulated that there is an important link between physical activity and functional status in later life. A statistically significant 14 year prospective study of 229 older women over concluded that $38 \%$ of the most active women experienced difficulties with their activities of daily living (ADLs), a measure of functional limitation, a stark contrast to $59.1 \%$ among those who were always inactive (27). Furthermore, a prospective study of 64 participants showed the combination of aerobic exercise and strength training to have a two-fold impact among older, frail individuals: increasing the $\mathrm{VO} 2$ peak by $14 \%$ and increasing muscle mass (28). This is further supported by a small study of older female participants that showed maximum aerobic capacity increased 30\% from baseline measurements following an exercise regimen (29). This is an important notion considering one of the leading causes of functional limitations among women is respiratory disease (30), partly due to the fact that the respiratory system is physiologically prone to significant decline in older age.

Similarly, multiple systematic reviews support the use of exercise as both a preventative measure and intervention for frailty among older women $(31,32)$. Of particular importance is the refutation of the notion of frailty as a static disease, hence providing optimism for potential resolution (33). So far, non-pharmacological intervention, in the form of specific exercise programmes, has shown favourable results and studies have suggested it can reverse the frailty status $(34,35)$. The focus on women with regards to frailty is relevant due to both its increased prevalence (36) and earlier onset in this group (37). Most studies demonstrated increased prevalence of frailty among women compared to men; $60.1 \%$ vs. $40.1 \%$ $(\mathrm{p}<.001)(38)$.

Next, considering reported frailty prevalence of around $10 \%$ of older people (and pre-frailty prevalence of up to $45 \%$ ) (36), and its increased prevalence and earlier onset in women (37), any advantages that exercise can confer 
to frail people will be significant. In fact, good physical condition has been shown to have an inverse relationship with frailty (34) and thus, many studies support the use of exercise as both a preventative measure and intervention for frailty among older women (31). Further, some studies suggest exercise could reverse the frailty status (35). This may be partly due to improvements in bone and muscle strength; weakened muscles and bones can increase the propensity to frailty (39). Exercise has been shown to directly target several areas specified in Fried's frailty assessment criteria, partly through improving ADLs (32), postponing disability (26) and increasing maximum aerobic capacity (29) and VO2 peaks (28).

Thirdly, associations between exercise and falls reduction are especially important for older women considering that they are more likely to fall than older men (40). Further, they are significantly more likely to be injured as a result of their fall (41). This may be due to menopause-related bone mass deterioration (osteoporosis) (40) or muscle weakness as a result of ageing or lifelong physical inactivity (41). Particularly when focussed on strength and balance, exercise has been consistently shown to improve bone density and decrease both the rate of total falls (42) and rate of injurious falls (43) in older women. Improvements in general physical functioning (43) and independence (44) have also been observed. Specifically, the exercise should be long-term, individually tailored and involve both group and homebased activities (42).

Given that older women experience accelerated bone mass and greater risk of osteoporosis compared to older men, it has been postulated that vitamin D supplementation may reduce the risk of falls amongst older women (40). However, as of yet, results of randomised controlled trials investigating the effects of vitamin D supplementation on falls have been inconsistent and rather, exercise may be a more effective strategy; a two year randomised, double-blind vitamin $\mathrm{D}$ and open exercise trial involving 409 older women in the community reported that while exercise improved physical functioning and reduced the rate of injurious falls, vitamin D did not yield such benefits (45).

Next, there are specific benefits of exercise for older women with nutritional problems. Physical activity, namely regular resistance and aerobic exercise, has been shown to increase muscle mass (44) and prevent sarcopenia (46) in older women. Sarcopenia, which describes loss of skeletal muscle mass and strength (47), is commonly seen in older people and especially in older women who are most at risk of protein malnutrition (48).

On the other hand, people between 65 and 74 years old have the highest prevalence of obesity and particularly, older women are more likely to be obese than older men (49). As a result, weight loss as a benefit of exercise (50) may most affect this group. Weight loss can improve physical functioning and independence (51) as well as reducing the risk of numerous health conditions, from cardiovascular disease (52) to osteoarthritis (53) and urinary incontinence (54). Furthermore, even independent of weight loss, exercise can reduce the risk of type-2 diabetes, and lead to reductions in systolic blood pressure (55) and the incidence of atrial fibrillation (52).

There are also benefits of exercise which are more salient in certain ethnic groups. For example, different ethnic groups are prone to specific diseases, many of which could be prevented or managed with exercise (56); diabetes is common in Asians, coronary heart disease in South Asians and stroke and hypertension in people from the Caribbean (57). Further, social and community aspects of exercise have been reported as amongst the most beneficial for many ethnic minority groups (56). Specifically, African Americans stated stress relief and time for meditation as key benefits whereas Chinese groups spoke about decreased medication and 'living longer and happier lives' (56 p.4). Management of pain, arthritis and hypertension are also reported (56). Although these benefits may be seen across the population, they could be most important to older ethnic women when taking into account the cumulative risks of being an older women as well as part of an ethnic minority group.

Menopausal women are another subgroup of older women who may observe specific benefits of exercise. Physical activity, particularly aerobic exercise (58), has been reported as an efficient and cost-effective (59) alternative to hormone replacement therapy for controlling menopause symptoms (58). In fact, physical inactivity before menopause has been shown to be associated with sleep problems, depression, anxiety and somatic symptoms after transition (60). Although controversial (61), many studies showed significant associations with exercise and reduced prevalence of vasomotor symptoms, including hot flushes and night sweats (62). This may be through increased levels of $\beta$-endorphin (63) or through weight loss (64). Evidence consistently shows associations between exercise and reduced sleep difficulties, depression and anxiety symptoms (65) and somatic symptoms such as migraines, paraesthesia and sexual problems (66). There is also some evidence for reductions in irritability and mood swings (62).

In spite of the growing body of evidence, only $28 \%$ of women in England between 55 and 64 years and 17\% between 65 and 74 years meet recommended activity levels. (67p.14). This is of particular concern in light of the changing demographics, in particular the exponential increase predicted of the 'oldest old' $(>85)$, the fastest growing population segment, in which frailty (36) and disability rates are highest; disability rates have been shown to triple between the age groups of 90-94 and 95+ (68).

Overall, exercise has many benefits for specific sub-groups of older women, but also more general advantages for all older women. Social and health-related advantages of exercise may improve population health, longevity and quality of life. 


\section{Some barriers to older women exercising}

Despite the abovementioned benefits of exercise for older women, this group is still amongst the most physically inactive (59). This is thought to be due to numerous perceived or actual barriers to exercise $(69,56)$. General barriers for all older women include physical exertion, expense, embarrassment and lack of time, motivation and facilities $(70,71)$. Additionally, cohort effects may be seen in older women who were raised to avoid vigorous exercise and choose exercises considered 'proper for girls' (70 p.318). Significantly, barriers have been shown to be more important in influencing exercise patterns than perceived benefits (72).

Importantly, it is postulated that functional limitations can be a product of the environment not providing sufficient support itself and thereby perpetuating the restraints (73). In fact, Verbrugge and Jette (74) established a distinction between intrinsic ability and actual ability, in which actual ability is an individual's ability in the context of support from the 'physical and social environment'. This would imply that a significant barrier to those with functional limitations is the access to provisional modification in the environment itself. In line with this, there is a lack of clear guidance with regards to the type of exercise and length of time required in order to observe benefits (75). Longitudinal studies have shown regular exercise to be a successful intervention in postponing shortened longevity and increased physical disability, two negative outcomes observed among functionally limited individuals (26, 33). An important consensus report concluded that the most beneficial approach to reduce the rate of muscle mass decline was the devising of specific exercise guidelines, a notion previously stated by the WHO Active-Ageing proposal (47).

The very nature of the underlying disease that causes any form of functional limitation results in a destructive feedback loop (17). Decreased strength is the intermediate between pathology and difficulty in ADL performance. In turn, reduced physical activity feeds back and deteriorates muscle strength. Frailty is not a contraindication to exercise, as historically believed, and as this paper has shown the benefits are extensive and outweigh the potential risks (39). Furthermore, few studies support the image that older people with disabilities or diseases are significantly more vulnerable to injury (32). One study reported that no myocardial infarctions, sudden death or other acute incidents were observed following a study of 80-100 year olds exercising in nursing homes (76). Clearly therefore, it is appropriate to reassure older people with functional limitations that the risk of a severe incident is very low. Indeed, the notion of psychosocial factors, most notably self-efficacy, has been prominent in multiple studies as a barrier to physical activity (77). In a cohort of older adults with knee OA, many were reluctant or less confident to climb stairs in contrast to the controls (78). Other studies yielded similar conclusions with regards specifically to exercise, gait and balance (79). Thus, there is clearly an underlying psychosocial aspect to functional limitations, which is positive in a sense as it can be modified, however it needs to be tackled.

Secondly, fear of falling has been reported to be independently associated with lower levels of physical activity (80). Moreover, both fear of falling and lower levels of physical activity have been reported to increase the risk of falling among older women (80). Therefore, exercise programmes to reduce falls in older women should also aim to address this fear (81). Lack of opportunities and facilities, age and gender-appropriate or not, have also been reported as barriers to exercise participation (82). In addition, older women may be unable to access available facilities as a result of caregiving responsibilities or transport and cost barriers (83). The latter may be especially pertinent for older women of lower socioeconomic status (83). Considering both retention and adherence to exercise regimes have been found to be greater in centre-based groups (84), these factors may be particularly detrimental to exercise levels.

Poor physical functioning and negative attitudes can also be considerable barriers to exercise for older women (85). This has been shown to be particularly true for frail older women, including those with sarcopenic obesity (85). Frailty itself, as determined by Fried's criteria, is a potential barrier to exercise (32). Psychological stress, often observed in obesity (86), is associated with a high-calorie and sugar diet (87) and reduced exercise motivation and adherence (86). Lack of motivation is more often stated as a barrier in older obese women than in younger age groups (88), possibly as a result of feeling uncomfortable, especially when exercising with people they perceive to be thinner, fitter or younger (89). Obesity-related joint pain and OA may also be barriers to exercise (53). Additionally, lack of clear guidance (74) and fear of worsening pain or injury (90) might deter some older women.

Next, there are some specific barriers to physical activity which may explain low levels of exercise in women from ethnic minorities (91). Firstly, family responsibilities have been reported as a barrier for older women in ethnic minority groups (92), whereas this is more commonly reported in younger women in the general population (10). This could be due to the high numbers of older ethnic women responsible for grandchild-care (93). Culture-specific expectations of women could also deter older women from participating in exercise (71). Likewise, lack of single-sex facilities or people from similar cultures, experiences of racism and issues with cultural or religious clothing could be barriers (57). The abovementioned higher prevalence of certain health conditions in some ethnic groups might play a role in reducing physical activity levels; fear of heart attack was sometimes cited as a reason for inactivity (21). Lastly, ethnic minority groups are often more socioeconomically 
disadvantaged than the general population (94). Low socioeconomic status (95) and related poverty and neighbourhood safety concerns (56) have been reported as barriers to exercise.

Lastly, women between 45 and 55 years (around menopause age) have been reported to have more perceived barriers to exercise than women over 55 (71). These include menopausal symptoms (70), such as pain (90) and fatigue (96). Furthermore, being overweight is often given as a reason for inactivity in women (69); considering the associations between menopause and weight gain, this barrier might be relevant for menopausal women (71).

Overall, there are many barriers to exercise observed in specific sub-groups of older women and the group as a whole. There is evidence, however, that these perceptions can be altered (97). As it is never too late to start exercising and benefit from the many advantages that it provides (98), further research into management and improvement of perceived barriers to exercise is needed.

\section{Conclusions}

As has been demonstrated there are numerous advantages for older people who undertake exercise, including an increase longevity and quality of life. Indeed, the World Health Organisation's World Report into Health and Ageing 2015 describes physical activity as a key behaviour influencing healthy ageing (99). However given that the prevalence of older women reaching the recommended activity levels is both low and decreases with age $(98,99)$, we have also considered the many barriers. Although some of these barriers are specific to the conditions it is suggested that there are some measures that can be taken which would affect most groups.

First is publicity about the value of exercise. This needs emphasising throughout life so that people enter old age both healthy and with any misconceptions about the risk of exercise addressed. Second is the targeting of this information for example at the surgeries of doctors and places where older people meet. Thirdly, there are issues of accessibility to places where exercise can take place such as gyms. Similarly, given the importance of walking, more should be done to make this easier and safer, for example, by ensuring that pavements are even and well maintained (99). However, the environmental restrictions of exercise are often linked to the socioeconomic status of individuals and it is important to remember when considering barriers that a lack of exercise may not be a lifestyle choice but a forced reality (98).

The findings, therefore, have implications for policy makers at an international, national and local level. But they also mean that older people themselves have to take some responsibility for their own health.
Neither the environment, nor socioeconomic status have been the focus of this article but are one of the wider implications that this article does not have the scope to expand upon $(98,99)$. These measures may take time to implement but it is never too late to change exercise behaviour and reap the benefits, giving an incentives to address the barriers to exercise and increase participation.

Ethical Standards: Ethical approval was not needed for this work as it was solely based on the literature.

Conflicts of interest: The authors confirm that there were no conflicts of interest.

\section{References}

1. Arber, $\mathrm{S}$ et al. "Maintaining health and well -being: Overcoming barriers to healthy ageing" in Walker, A (ed) The New Science of Ageing, the Policy Press, Bristol, 2014;pp 113 - 154

2. Taylor, D. Physical activity is medicine for older adults, Postgraduate Medical Journal 2014;14: 90, 26-32

3. Health and Social Care Information Centre (HSCIC). Health Survey for England 2012, Joint Health Surveys Unit, NatCen and Department of Epidemiology and Public Health University College London: London, 2012

4. Department of Health in England (DH), the Scottish Government (SG) the Welsh Office (WO) and the Department of Health in Northern Ireland (DHSSPS) 2011a

5. Caspersen, CJ, Powell, KE, Christienson, GM. "Physical activity, exercise, and physical fitness: definitions and distinctions for health-related research", Public Health Reports, March-Apr 1985;100: 2, 126-131

6. The American Council on Exercise (ACE). Physical Activity versus Exercise: What's the Difference? 3.6.15 ACE, San Diego, California, USA, 2015

7. DH, SG, WO, DHSSPS. (11.7.11) Start Active, Stay Active, and a Fact Shee 'Physical activity guidelines for older adults (65+ years)' DH, London, 2011b.

8. Women's Sport and Fitness Foundation, (WSFF,). Physical activity and older women, WSFF, London, 2005

9. Department for Work and Pensions (DWP). Older Workers: Statistical Information booklet 2013 Official Statistics. 12.12.13. DWP, London, 2013

10. Zunft, H.J., Friebe, D., Seppelt, B., Widhalm, K., Remaut de Winter, A.M., Vaz de Almeida, M.D., Kearney, J.M. \& Gibney, M. "Perceived benefits and barriers to physical activity in a nationally representative sample in the European Union", Public Health Nutrition, 1999;2: 1A, 153-160.

11. Stojanovska, L., Apostolopoulos, V., Polman, R. \& Borkoles, E. "To exercise, or, not to exercise, during menopause and beyond", Maturitas, 2014;77: 4, 318323

12. Hu F.B., Sigal R.J., Rich-Edwards J.W., Colditz G.A., Solomon C.G., Willett W.C., Speizer F.E. \& Manson J.E. "Walking compared with vigorous physical activity and risk of type 2 diabetes in women: A prospective study", Journal of the American Medical Association, 1999;282: 15, 1433-1439.

13. Mori T., Ishii S., Greendale G.A., Cauley J.A., Sternfeld B., Crandall C.J., Han W. \& Karlamangla A.S. "Physical activity as determinant of femoral neck strength relative to load in adult women: Findings from the hip strength across the menopause transition study", Osteoporosis International, 2014;25: $1,265-272$.

14. Manson, J.E., Greenland, P., LaCroix, A.Z., Stefanick, M.L., Mouton, C.P., Oberman, A., Perri, M.G., Sheps, D.S., Pettinger, M.B. \& Siscovick, D.S. "Walking compared with vigorous exercise for the prevention of cardiovascular events in women", The New England Journal of Medicine, 2002;347: 10, 716-725

15. Von Bonsdorff, M.B. \& Rantanen, T. "Progression of functional limitations in relation to physical activity: a life course approach", European Review of Aging and Physical Activity, 2011;8: 1, 23-30.

16. Crocker, T., Forster, A., Young, J., Brown, L., Ozer, S., Smith, J., Green, J., Hardy, J., Burns, E., Glidewell, E. \& Greenwood, D.C. "Physical rehabilitation for older people in long-term care", The Cochrane database of systematic reviews, 2013; vol. (2):CD004294. doi, no. 2, CD004294.

17. Rantanen, T, Guralnik, J.M., Sakari-Rantala, R, Leveille, S, Simonsick, E.M Ling, S. and Fried, L.P. "Disability, physical activity, and muscle strength in older women: the Women's Health and Aging Study." Archives of physical medicine and rehabilitation, 1999;80: 2, 130-135.

18. La Croix AZ, Leveille S, Hecht J, Grothaus L, Wagner E. “Does walking reduce the risk of cardiovascular disease and death in older adults?", J Am Geriatr Soc, 1996;44: 113-120

19. Clark, D.O. "The effect of walking on lower body disability among older blacks and whites", American Journal of Public Health, 1996;86:1, 57-61.

20. Gillum RF, Mussolino ME, Ingram DD. "Physical activity and stroke incidence in women and men. The NHANES I Epidemiologic Follow-up Study", Am J Epidemiol, 1996;143:860-869

21. Eyler, A.A., Baker, E., Cromer, L., King, A.C., Brownson, R.C. \& Donatelle, 
R.J. "Physical Activity and Minority Women: A Qualitative Study", Health Education \& Behavior, 1998;25: 5, 640-652.

22. Penninx, B.W., Messier, S.P., Rejeski, W.J., Williamson, J.D., DiBari, M., Cavazzini, C., Applegate, W.B. and Pahor, M. Physical exercise and the prevention of disability in activities of daily living in older persons with osteoarthritis. Archives of Internal Medicine, 2001;161: 19, 2309-2316.

23. Liu, C.J. \& Latham, N.K. "Progressive resistance strength training for improving physical function in older adults", The Cochrane database of systematic reviews, vol. (3):CD002759. doi, no. 3, CD002759.

24. Sherman, S.E., D'Agostino, R.B., Cobb, J.L. and Kannel, W.B. Physical activity and mortality in women in the Framingham Heart Study. American Heart Journal, 1994:128: 5, 879-884.

25. Nicklett, E.J., Semba, R.D., Xue, Q.L., Tian, J., Sun, K., Cappola, A.R., Simonsick, E.M., Ferrucci, L. \& Fried, L.P. "Fruit and vegetable intake, physical activity, and mortality in older community-dwelling women", Journal of the American Geriatrics Society, 2012;60: 5, 862-868.

26. Leveille SG, Guralnik JM, Ferrucci L, Langlois JA. “Aging successfully until Death in Old Age: Opportunities for Increasing Active Life Expectancy", Am J Epidemiol 1999; vol 149: 7: 654-664

27. Brach, J.S., FitzGerald, S., Newman, A.B., Kelsey, S., Kuller, L., VanSwearingen, J.M. \& Kriska, A.M. "Physical activity and functional status in community-dwelling older women: a 14-year prospective study", Archives of Internal Medicine, 2003;163: 21, 2565-2571.

28. Ehsani A, Spina RJ et al. "Attenuation of cardiovascular adaptations to exercise in frail octogenarians" Journal of Applied Physiology, 2003;95: 5 , $1781-1788$

29. Harber M, Konopka A et al. "Aerobic exercise training improves whole muscle and single myofiber size and function in older women" Am J Physiol Regul Integr Comp Physiol. 2009;297: 51452 - 1459

30. European Commission. Healthy life year statistics [Internet]. Eurostat 2016 [Cited 15 December 2016]. Available from http://ec.europa.eu/eurostat/ statistics-explained/index.php/Healthy_life_years_statistics

31. Chou, Chih-Hsuan et al. "Effect of Exercise on Physical Function, Daily Living Activities, and Quality of Life in the Frail Older Adults: A MetaAnalysis", Archives of Physical Medicine and Rehabilitation, 2012;93: 2, 237244

32. Liu, C. K., \& Fielding, R. A. "Exercise as an Intervention for Frailty", Clinics in Geriatric Medicine, 2011;27: 1, 101-110.

33. Morley, J. E., Vellas, B., van Kan, G. A., Anker, S. D., Bauer, J. M., Bernabei, R., Walston, J. "Frailty Consensus: A Call to Action." Journal of the American Medical Directors Association, 2013;14: 6, 392-397.

34. Faber M, Bosscher et al. "Effects of exercise programs on falls and mobility in frail and pre-frail older adults: A multicenter randomized controlled trial" Arch Phys Med Rehabil, 2006;87: 885-96.

35. Buckin, Rolland et al. "Burden of frailty in the elderly population: perspectives for a public health challenge", Archives of Public Health, 2015;73: 19

36. Clegg A, Young J, et al. "Frailty in elderly people", The Lancet, 2013;381: 752762

37. Kang, SJ. "Comparison of ageing threshold and aging coefficient in health related physical fitness on Korean and Japanese", Korean Journal of Physical Education, 2007;46: 723-736.

38. Chen, C.Y., Wu, S.C., Chen, L.J. \& Lue, B.H. "The prevalence of subjective frailty and factors associated with frailty in Taiwan", Archives of Gerontology and Geriatrics, 2010;50: 1, S43-7.

39. Chodzko-Zajko WJ, Proctor DN et al. "American College of Sports Medicine, American college of sports medicine position stand, Exercise and physical activity for older adults", Med Sci Sports Exerc, 2009;41: 7, 1510-1530

40. Yoshida-Intern, S. (A Global Report on Falls Prevention Epidemiology of Falls. WHO. Geneva,

41. Stevens, J.A. and Sogolow, E.D. Gender differences for non-fatal unintentional fall related injuries among older adults. Injury Prevention, 2005;11: 2, 115-119.

42. El-Khoury, F., Cassou, B., Latouche, A., Aegerter, P., Charles, M.A. And Dargent-Molina, P. "Effectiveness of two year balance training programme on prevention of fall induced injuries in at risk women aged 75-85 living in community: Ossebo randomised controlled trial", BMJ (Clinical research ed.), 2015;351: h3830.

43. Patil, R., Uusi-Rasi, K., Tokola, K., Karinkanta, S., Kannus, P. And Sievänen, H. "Effects of a Multimodal Exercise Program on Physical Function, Falls, and Injuries in Older Women: A 2-Year Community-Based, Randomized Controlled Trial", Journal of the American Geriatrics Society, 2015;63: 7, 13061313.

44. Christmas, C. \& Andersen, R.A. "Exercise and older patients: guidelines for the clinician", Journal of the American Geriatrics Society, 2000;48: 3, 318-324.

45. Uusi-Rasi, K., Patil, R., Karinkanta, S., Kannus, P., Tokola, K., LambergAllardt, C. and Sievänen, H. Exercise and vitamin D in fall prevention among older women: a randomized clinical trial. JAMA Internal Medicine, 2015;175: 5, 703-711.

46. Morley, J.E., Argiles, J.M., Evans, W.J., Bhasin, S., Cella, D., Deutz, N.E., Doehner, W., Fearon, K.C., Ferrucci, L., Hellerstein, M.K., Kalantar-Zadeh, K., Lochs, H., MacDonald, N., Mulligan, K., Muscaritoli, M., Ponikowski, P.,
Posthauer, M.E., Rossi Fanelli, F., Schambelan, M., Schols, A.M., Schuster M.W., Anker, S.D. \& Society for Sarcopenia, Cachexia, and Wasting Disease "Nutritional recommendations for the management of sarcopenia", Journal of the American Medical Directors Association, 2010;11: 6, 391-396.

47. Cruz-Jentoft, A.J., Baeyens, J.P., Bauer, J.M., Boirie, Y., Cederholm, T., Landi, F., Martin, F.C., Michel, J.P., Rolland, Y., Schneider, S.M., Topinkova, E., Vandewoude, M., Zamboni, M. \& European Working Group on Sarcopenia in Older People. "Sarcopenia: European consensus on definition and diagnosis: Report of the European Working Group on Sarcopenia in Older People", Age and Ageing, 2010;39: 4, 412-423.

48. Morley JE. Nutrition and the older female: a review. Journal of the American College of Nutrition. 1993;1: 12, 4:337-4343.

49. Public Health England 2015, Adult obesity prevalence by age and sex Available: http:/ / www.noo.org.uk/NOO_about_obesity/inequalities [2015, 12/18].

50. Pronk, N.P. \& Wing, R.R. "Physical Activity and Long-Term Maintenance of Weight Loss", Obesity Research, 1994;2: 6, 587-599.

51. Bouchard, D.R., Soucy, L., Sénéchal, M., Dionne, I.J. \& Brochu, M. "Changes in objective and self-reported measures of physical capacity after an intervention in obese older women", Journal of Women \& Aging, 2010;22: 1, 34-46.

52. Azarbal, F., Stefanick, M.L., Salmoirago-Blotcher, E., Manson, J.E., Albert, C.M., LaMonte, M.J., Larson, J.C., Li, W., Martin, L.W., Nassir, R., Garcia, L., Assimes, T.L., Tharp, K.M., Hlatky, M.A. \& Perez, M.V. "Obesity, physical activity, and their interaction in incident atrial fibrillation in postmenopausal women", Journal of the American Heart Association, 2014;3: 4, 10.1161/ JAHA.114.001127.

53. Messier, S.P., Loeser, R.F., Miller, G.D., Morgan, T.M., Rejeski, W.J., Sevick, M.A., Ettinger, W.H., Pahor, M. \& Williamson, J.D. "Exercise and dietary weight loss in overweight and obese older adults with knee osteoarthritis: the Arthritis, Diet, and Activity Promotion Trial", Arthritis \& Rheumatism, 2004;50: 5, 1501-1510.

54. Subak, L.L., Wing, R., West, D.S., Franklin, F., Vittinghoff, E., Creasman, J.M., Richter, H.E., Myers, D., Burgio, K.L. \& Gorin, A.A. "Weight loss to treat urinary incontinence in overweight and obese women", New England Journal of Medicine, 2009:360: 5, 481-490.

55. Kang, S. "Trekking exercise promotes cardiovascular health and fitness benefits in older obese women", Journal of Exercise Rehabilitation, 2014;10: 4, 225.

56. Belza, B., Walwick, J., Schwartz, S., LoGerfo, J., Shiu-Thornton, S. \& Taylor, M. "Older Adult Perspectives on Physical Activity and Exercise: Voices From Multiple Cultures", Preventing Chronic Disease, 2004;1: 4, A09.

57. Health Education Authority 1997. Promoting physical activity with black and minority ethnic groups: guidelines for practice. London: Health Education Authority.

58. Royal College of Obstetricians and Gynaecologists, 2010. Alternatives to HRT for the Management of Symptoms of the Menopause. Scientific Impact Paper No. 6. London: Royal College of Obstetricians and Gynaecologists

59. Kolu P., Raitanen J., Nygård C.-H., Tomás E. \& Luoto R. "Cost-effectiveness of physical activity among women with Menopause symptoms: Findings from a randomised controlled trial", PLoS ONE, 2015;10: 8.

60. Hunter, M. "Longitudinal Studies of the Climacteric. The South-East England longitudinal study of the climacteric and postmenopause", Maturitas, 1992;4: 2, 117-126.

61. Daley, A., Stokes-Lampard, H., Thomas, A. \& MacArthur, C. "Exercise for vasomotor menopausal symptoms", The Cochrane database of systematic reviews, 2014;11,. CD006108.

62. Moilanen J.M., Mikkola T.S., Raitanen J.A., Heinonen R.H., Tomas E.I., Nygård C.-H. \& Luoto R.M. "Effect of aerobic training on menopausal symptoms-a randomized controlled trial", Menopause, 2012;19: 6, 691-696.

63. Hammar, M., Berg, G. \& Lindgren, R. "Does Physical Exercise Influence the Frequency of Postmenopausal Hot Flushes?", Acta Obstetricia et Gynecologica Scandinavica, 1990;69: 5, 409-412.

64. Huang, A.J., Subak, L.L., Wing, R. et al. "An intensive behavioural weight loss intervention and hot flushes in women", Archives of Internal Medicine, 2010;170: 13, 1161-1167.

65. Sternfield, B., Guthrie, K.A., Ensrud, K.E., LaCroix, A.Z., Larson, J.C., Dunn A.L., Anderson, G.L., Seguin, R.A., Carpenter, J.S., Newton, K.M., Reed, S.D., Freeman, E.W., Cohen, L.S., Joffe, H., Roberts, M. \& Caan, B.J. ("Efficacy of Exercise for Menopausal Symptoms: A Randomized Controlled Trial", Menopause (New York, N.Y.), 2014;21: 4, 330-338

66. Javadivala Z., Kousha A., Allahverdipour H., Jafarabadi M.A. \& Tallebian $\mathrm{H}$. "Modeling the relationship between physical activity and quality of life in menopausal-aged women: A cross-sectional study", Journal of Research in Health Sciences, 2013;13: 2, 168-175.

67. Townsend N, Bhatnagar P, Wickramasinghe K, Scarborough P, Foster C, Rayner M. Physical activity statistics 2012. British Heart Foundation: London, pp 14, 2012.

68. Berlau, D.J., Corrada, M.M., Peltz, C.B. \& Kawas, C.H. "Disability in the oldest-old: incidence and risk factors in the 90+ study", The American Journal of Geriatric Psychiatry : Official Journal of the American Association for Geriatric Psychiatry, 2012;20: 2, 159-168. 
69. Booth, M.L., Bauman, A., Owen, N. \& Gore, C.J. "Physical activity preferences, preferred sources of assistance, and perceived barriers to increased activity among physically inactive Australians", Preventive Medicine, 1997;26: 1, 131-137.

70. Im, E., Lee, B., Chee, W., Stuifbergen, A. \& The eMAPA, R.T. "Attitudes toward Physical Activity of White Midlife Women", Journal of obstetric, gynecologic, and neonatal nursing : JOGNN / NAACOG, 2011;40: 3, 312-321.

71. McGuire, A.M. 2015. Benefits and barriers to exercise in midlife women undertaking a web-based multi-modal lifestyle intervention for the primary prevention of chronic disease, Queensland University of Technology.

72. Pender, N. 1996. Health Promotion in Nursing Practice. (third ed) Appleton \& Lange, Stamford, CT

73. Iwarsson, S. "A long-term perspective on person-environment fit and ADL dependence among older Swedish adults", The Gerontologist, 2005;45: 3, 327336.

74. Verbrugge, L.M. \& Jette, A.M. "The disablement process", Social Science \& Medicine, 1994;38: 1, 1-14.

75. Bandeen-Roche K, Xue QL et al. "Phenotype of frailty: characterization in the women's health and aging studies" J Gerontol A Biol Sci Med Sci, 2006;61: 262-266

76. Zak, M., Swine, C. \& Grodzicki, T. "Combined effects of functionallyoriented exercise regimens and nutritional supplementation on both the institutionalised and free-living frail elderly (double-blind, randomised clinical trial)", BMC Public Health, 2009;9: 1, 39.

77. McAuley, E. \& Blissmer, B. "Self-efficacy determinants and consequences of physical activity", Exercise and Sport Sciences Reviews, 2000;28: 2, 85-88.

78. Rejeski, W.J., Ettinger, W.H.Jr, Martin, K. \& Morgan, T. "Treating disability in knee osteoarthritis with exercise therapy: a central role for self-efficacy and pain", Arthritis Care and Research : The Official Journal of the Arthritis Health Professions Association, 1998;11: 2, 94-101.

79. Seeman, T. \& Chen, X. "Risk and protective factors for physical functioning in older adults with and without chronic conditions: MacArthur Studies of Successful Aging", The Journals of Gerontology. Series B, Psychological Sciences and Social Sciences, 2002;57: 3, S135-44.

80. Patil, R., Uusi-Rasi, K., Kannus, P., Karinkanta, S. And Sievanen, H "Concern about falling in older women with a history of falls: associations with health, functional ability, physical activity and quality of life", Gerontology, 2014;60: 1, 22-30.

81. Doi, T., Ono, R., Ono, K., Yamaguchi, R., Makiura, D. And Hirata, S. "The association between fear of falling and physical activity in older women", Journal of Physical Therapy Science, 2012;24: 9, 859-862.

82. Schutzer, K.A., Graves, B.S. Barriers and motivations to exercise in older adults. Preventive Medicine, 2004;39: 5,1056-1061.

83. Kowal, J. And Fortier, M.S. "Physical activity behavior change in middle-aged and older women: the role of barriers and of environmental characteristics", Journal of Behavioural Medicine, 2007;30: 3, 233-242

84. Cox, K.L., Burke, V., Gorely, T.J., Beilin, L.J. \&Puddey, I.B. “Controlled Comparison of Retention and Adherence in Home- vs Center-Initiated Exercise Interventions in Women Ages 40-65 Years: The S.W.E.A.T. Study (Sedentary Women Exercise Adherence Trial)", Preventive Medicine, 2003;36:
1, 17-29.

85. Heath, J.M. \& Stuart, M.R. "Prescribing exercise for frail elders", The Journal of the American Board of Family Practice / American Board of Family Practice, 2002;15: 3, 218-228.

86. Laugero KD, Falcon LM \& Tucker KL. "Relationship between perceived stress and dietary and activity patterns in older adults participating in the Boston Puerto Rican Health Study.", Appetite, 2011;56: 1, 194-204.

87. Pecoraro, N., Reyes, F., Gomez, F., Bhargava, A. \& Dallman, M.F. "Chronic stress promotes palatable feeding, which reduces signs of stress: feedforward and feedback effects of chronic stress", Endocrinology, 2004;145: 8, 3754-3762.

88. Sharifi, N., Mahdavi, R. \& Ebrahimi-Mameghani, M. "Perceived barriers to weight loss programs for overweight or obese women", Health Promotion Perspectives, 2013;3: 1, 11.

89. Caserta, M.S. \& Gillett, P.A. "Older women's feelings about exercise and their adherence to an aerobic regimen over time", The Gerontologist, 1998;38: 5, 602-609.

90. Lucas, J.A., Orshan, S.A. \& Cook, F. 2000. "Determinants of health-promoting behavior among women ages 65 and above living in the community", Scholarly inquiry for nursing practice, 14: 1, 77-100; discussion 101-9.

91. Castro, C.M., Sallis, J.F., Hickmann, S.A., Lee, R.E. \& Chen, A.H. "A prospective study of psychosocial correlates of physical activity for ethnic minority women", Psychology \& Health, 1999;14: 2, 277-293.

92. King, A.C., Castro, C., Wilcox, S., Eyler, A.A., Sallis, J.F. \& Brownson, R.C "Personal and environmental factors associated with physical inactivity among different racial-ethnic groups of U.S. middle-aged and older-aged women", Health psychology : official journal of the Division of Health Psychology, American Psychological Association, 2000;19: 4, 354-364.

93. Mutchler, J., Lee, S., Baker, L.A. 2002. "Grandparent Care in the United States: Comparisons by Race and Ethnicity". Gerontology Institute Publications. Paper 24

94. Barer R, Marshall J, Fitzpatrick L, Cragg, Jacobson B. 2004 Health in London report. London: GLA, London Health Commission, London Health Observatory.

95. Eyler, A.E., Wilcox, S., Matson-Koffman, D., Evenson, K.R., Sanderson, B., Thompson, J., Wilbur, J. \& Rohm-Young, D. "Correlates of physical activity among women from diverse racial/ethnic groups", Journal of Women's Health \& Gender-based Medicine, 2002;11: 3, 239-253.

96. Chu, T., Jeng. C., Lee, P. 2012; "Exercise Stages, Benefits, and Barriers among Menopausal Women". Available at: http://libir.tmu.edu.tw / bitstream/987654321/45689/2/

97. Brinthaupt, T.M., Kang, M. \& Anshel, M.H. "A delivery model for overcoming psycho-behavioral barriers to exercise", Psychology of Sport and Exercise, 2010;11: 4, 259-266.

98. International Longevity Centre - Brazil (ILC - Brazil), 2015 "Active Ageing A Policy Framework in Response to the Longevity Revolution", International Longevity Centre - Brazil, Brazil

99. World Health Organization, World report on ageing and health Luxembourg, Luxembourg, 2015;1-260. 